\title{
Differential expression of glucose transporter GLUT8 during mouse spermatogenesis
}

\author{
Olga Gómez, Amparo Romero ${ }^{1}$, José Terrado and José E Mesonero ${ }^{1}$ \\ Department of Medicine and Animal Surgery and ${ }^{1}$ Department of Physiology, Pharmacology and Toxicology, \\ Experimental Sciences and Health Faculty, Cardenal Herrera - CEU University, E-46113-Moncada, Valencia, Spain
}

Correspondence should be addressed to J E Mesonero, who is now at Physiology, Veterinary Faculty, University of Zaragoza, Miguel Servet, 177, E-50013-Zaragoza, Spain; Email: mesonero@unizar.es

O Gómez and A Romero contributed equally to this work

\begin{abstract}
GLUT8 is a facilitative glucose transporter expressed at high levels in the testis. In this study, we analyzed the GLUT8 expression in mouse testis during spermatogenesis by RT-PCR, Western blot and immunohistochemistry methods. Our results show that GLUT8 expression is limited to spermatids and spermatozoa in the testis. Expression begins when round spermatids are formed at postnatal day 24. The expression persists throughout spermiogenesis, and it is also detected in spermatozoa, but it is absent in more immature germ cells, Sertoli cells and interstitial tissue. GLUT8 immunoreactivity is always restricted to the acrosomic system in a manner that matches the acrosome system formation. The GLUT8 expression is mainly associated with the acrosomic membrane in the acrosome, although significant immunoreactivity is also found inside the acrosomic lumen. The specific GLUT8 location suggests that this transporter plays a pivotal role in the fuel supply of spermatozoa, and in the traffic of sugars during the capacitation and fertilization processes.

Reproduction (2006) 131 63-70
\end{abstract}

\section{Introduction}

Glucose is the fuel and also an important metabolic substrate for most mammalian cells. The family of facilitative glucose transporter (GLUT) proteins is responsible for the entry of glucose into mammalian cells. At present, 13 members of the GLUT family with different substrate specificities, kinetics properties and tissue-expression profiles have been described (Uldry \& Thorens 2004). On the basis of their structural and functional characteristics, and of their sequence alignment, GLUT family members have been classified into three subclasses (Joost \& Thorens 2001, Wood \& Trayhurn 2003). GLUT8 is a recently cloned member of class III facilitative transporters, which are expressed to a certain extent in heart, skeletal muscle, brain, spleen, prostate and intestine, but their expression levels are highest in testis (Carayannopoulos et al. 2000, Doege et al. 2000, Ibberson et al. 2000). GLUT8 is also expressed in the murine blastocyst, where it is important for blastocyst survival, and it seems to be regulated by the insulin/insulin-like growth factor-1 (IGF-1) signaling pathways through the IGF-1 receptor (IGF1-R) (Carayannopoulos et al. 2000, Pinto et al. 2002).
On the basis of its expression levels, GLUT8 appears to be one of the main glucose transporters in testis. GLUT8 has a high glucose transport activity (Doege et al. 2000, Ibberson et al. 2000) that is inhibitable by fructose (Ibberson et al. 2000). In spite of the fact that it is mainly expressed in testis, with a possible function of glucose and fructose transport, the precise localization of this protein in testicular cells remains unclear and controversial. It has been reported that GLUT8 expression is restricted to the type I spermatocytes in the rat (Ibberson et al. 2002), in the innermost cells within the seminiferous tubules and spermatozoa in mice and man (Schürmann et al. 2002), and in rat Leydig cells (Chen et al. 2003). It has also been reported that GLUT8 seems to be hormonally regulated in testis, since it is detected neither in testicular carcinoma nor under estrogen treatment (Doege et al. 2000).

The higher GLUT8 expression levels in the testis than in other tissues, in addition to the particular hexose metabolism of testicular cells, which bear a different glycolytic status according to their developmental stage, suggest an interesting yet unelucidated role for this transporter in this tissue. To clarify the concrete expression sites of GLUT8 in the testis, we have analyzed GLUT8 distribution in mouse testis of different ages by means of reverse 
transcription (RT)-PCR, Western blot and immunohistochemistry. Our results show that GLUT8 expression starts as soon as early spermatids are differentiated, and that the expression is present in all spermatids and spermatozoa, where is it found to be restricted to the acrosomal region. The concrete and specific localization of GLUT8 strongly suggests a physiologic role of this transporter not only in internal glucose movement, but also in the traffic of sugars during the capacitation and fertilization processes.

\section{Materials and Methods}

\section{Animals}

Handling, the equipment used and the killing of animals were all in accordance with European Council regulation $86 / 609 /$ EEC on experimental animal protection. Male CD1 mice of 8-10 weeks of age and reproductive female mice were obtained from Harlan Iberica S.L. (Barcelona, Spain). Breeding pairs of CD1 mice were monitored daily for litters, and the day of birth was taken as day 0. All animals were maintained on a $12 \mathrm{~h}$ day-night cycle, at constant room temperature $\left(22^{\circ} \mathrm{C}\right)$, with free access to water and standard mouse fodder. All experimental protocols were approved by the ethics committee of the Cardenal Herrera-CEU University.

\section{Materials}

All generic reagents were obtained from either Sigma or Roche.

Hybond membranes and enhanced chemiluminescence (ECL) detection system and antirabbit IgG secondary antibody were obtained from Amersham. Bradford and Western blotting reagents were from Bio-Rad.

Rabbit polyclonal antibody against actin was obtained from Sigma. Synthetic peptide (LEQVTAHFEGR) corresponding to the 11 C-terminal residues $(467-477)$ of mouse GLUT8 with a terminal cysteine was prepared by Q-Biogene (Illkirch, France). The N-terminal amino acid was cross-linked to $\mathrm{KLH}$ by $\mathrm{m}$-maleimidobenzoic acid $\mathrm{N}$-hydroxysuccinimide ester (MBS), and polyclonal antibodies against the peptide were produced in rabbit.

\section{Tissue preparation}

Groups (four animals per group) of male adult mice (8-10 weeks old), and male mice pups of 14 and 24 days of age were killed by cervical dislocation. After dissection, the left testis of each animal was fixed for immunohistochemical analysis. The other testes were frozen at $-80^{\circ} \mathrm{C}$ until subsequently used for protein and RNA extraction.

\section{Reverse transcription-polymerase chain reaction (RT-PCR)}

Total RNA was extracted from isolated testes with RNeasy Mini Kit and QIAshredder columns (Qiagen), as previously described (Mesonero et al. 2000). Reverse transcription was performed with $2 \mu \mathrm{g}$ total RNA. cDNA was synthesized with Oligo dT and Superscript II Reverse Transcriptase (Invitrogen). PCR was performed with oligonucleotide primers specific for mouse GLUT8 (GenBank accession number NM0194881) and GAPDH (GenBank accession number BC083149), using a thermocycler GeneAmp PCR2700 (Applied Biosystems, FosterCity, CA, USA). Primer sequences $\left(5^{\prime}-3^{\prime}\right)$ were as follows: GLUT8 forward ATCTCCGAAATCGCCTACCC, GLUT8 reverse ATTATGCCCACAGTGACC, GAPDH forward CATCACCATCTTCCAGGAGC, and GAPDH reverse CACGGAAGGCCATGCCAG. The amplification of GLUT8 (507 pb) and GAPDH (485 pb) were performed at $94^{\circ} \mathrm{C}$ for $30 \mathrm{~s}, 58^{\circ} \mathrm{C}$ for $30 \mathrm{~s}$ and $72{ }^{\circ} \mathrm{C}$ for $60 \mathrm{~s}$, for 35 cycles. The PCR products were resolved on $1 \%$ agarose gels and visualized by ethidium bromide staining. Control reactions were performed with the primers in the absence of CDNA. PCR reactions were performed three times in two independent experiments.

\section{Histologic and immunohistochemical methods}

Testes were placed in Bouin's fixative for periods from $6 \mathrm{~h}$ to overnight, depending on the size of the testis. After fixation, the tissues were dehydrated in increasing concentrations of ethanol, embedded in paraffin, serially sectioned $(3 \mu \mathrm{m})$ with a HM 310 Microm microtome, and collected on polylysine-coated slides. Sections were deparaffined, rehydrated, incubated with $3 \% \mathrm{H}_{2} \mathrm{O}_{2}$ in methanol for 20 min to quench endogenous peroxidase activity, and processed for immunohistochemical analysis with an antiGLUT8 antibody. Immunohistochemistry for GLUT8 was performed by the immunoperoxidase procedure of the Vectastain Elite ABC kit (Vector Laboratories, Burlingame, CA, USA), according to the manufacturer's instructions, with rabbit anti-GLUT8 polyclonal antiserum (dilution 1:500) and diaminobenzidine tetrahydrochloride (DAB) substrate (Vector Laboratories). Nonspecific antibody binding was blocked with $10 \%$ normal goat serum. Negative control sections were prepared by replacing the primary antibody with nonimmune serum from rabbit. Immunohistochemical analyses were performed at least twice in three independent experiments. Some sections were stained with hematoxylin and eosin to identify cell morphology, or they were stained with PAS (periodic acid-Schiff staining) to identify the acrosome (Leblond \& Clermont 1952, Russell et al. 1990). To study GLUT8 expression in spermatozoa, fresh mouse epididymides were incised with a scalpel, and samples of the content were obtained with sterile swabs and extended on slides. Then, GLUT8 immunoreactivity was investigated as on the testis sections.

\section{Immunoblotting}

Western blotting was performed with $40 \mu \mathrm{g}$ total protein. Protein concentration was determined by the method of 
Bradford (1976). Protein samples were analyzed by SDS-PAGE in 10\% acrylamide gels, as described by Laemmli (1970), and the proteins were then transferred to Hybond-ECL membranes that were blocked for $2 \mathrm{~h}$ in $5 \%$ nonfat dried milk in Tris-buffered saline (TBS) $(20 \mathrm{mM}$ Tris- $\mathrm{HCl}(\mathrm{pH} \mathrm{7.5)}$ and $500 \mathrm{mM} \mathrm{NaCl}$ ). The blots were probed with rabbit polyclonal anti-GLUT8 antibody, used at a 1:800 dilution. The primary antibody was detected with antirabbit IgG antibody coupled to horseradish peroxidase (dilution 1:2000), using the ECL detection system. The blots were reprobed after stripping in $62.5 \mathrm{mM}$ Tris$\mathrm{HCl}(\mathrm{pH}$ 6.7), 2\% SDS and $100 \mathrm{mM} \beta$-mercaptoethanol for $60 \mathrm{~min}$ at $60^{\circ} \mathrm{C}$. Nitrocellulose sheets were rinsed in TBS and then reblotted for 60 min in 5\% nonfat dried milk in TBS before being probed with antiactin antibody (A5060; Sigma) at 1:300 dilution. The specificity of the primary antibody was demonstrated by its preadsorption with the corresponding control peptide. The amplitude of the signal was verified as being proportional to the amount of proteins loaded on the gels, at least within the investigated range $(10-50 \mathrm{mg})$. Thus, the bindings of primary and secondary antibodies, as well as the ECL reaction, were not limiting.

\section{Results}

\section{GLUT8 expression by Western blot analysis}

We first analyzed the presence of GLUT8 in testis by Western immunoblots analysis using a polyclonal rabbit antiserum against a short C-terminus peptide of mouse GLUT8. As Fig. 1A illustrates, the antiserum detected a $42-45 \mathrm{kDa}$ protein in adult testis. A second specific band was also detected at approximately $75 \mathrm{kDa}$. Other groups have also detected this second band in several expression systems, such as reticulocyte lysates and HEK293T cells (Ibberson et al. 2000) and COS-7-transfected cells (Doege et al. 2000, Schürmann et al. 2002), and in mouse liver and kidney tissues (Gorovits et al. 2003, Schiffer et al. 2005). Since glucose transporters tend to aggregate even under denaturing conditions, this band might represent a homodimer of GLUT8, because its intensity relative to the lower band depends in part on the cell lysis conditions, in particular on the addition of reducing agents (Ibberson et al. 2000). When the antiserum was blocked with the antigenic peptide, both specific signals (42 and $75 \mathrm{kDa}$ ) disappeared, indicating that this anti-GLUT8 antibody specifically detects the facilitative glucose transporter GLUT8.

After verifying the specificity of our antibody antiGLUT8, we compared the expression of GLUT8 in adult, 24-day-old and 14-day-old mice. Since the higher band was always proportional to the intensity of lower band, we analyzed the protein expression of GLUT8 corresponding to the monomeric form of $42 \mathrm{kDa}$. No GLUT8 expression was detected in 14-day-old mice, whereas in 24-day-old and adult mice a band of the expected size was evident (Fig. 1B). The intensity of the band was higher in adult than in 24-day-old animals, suggesting that GLUT8 begins to be expressed at approximately this early stage.

\section{GLUT8 immunohistochemical detection during mouse testis maturation}

In order to confirm the absence of GLUT8 expression in prepuberal mouse testis, and to determine the stage of germ-cell differentiation at which GLUT8 first appears, we studied its expression in tissue sections obtained from mice of different ages on the basis of the type of germ cells found at each time. Tissues from 14-day-, 24-day-, and 8-10-week-old mouse testis were analyzed with the C-terminus anti-GLUT8 antibody by the experimental procedure described in Materials and Methods. Results are summarized in Table 1.

Immunochemical analysis of testicular sections in 14day-old mice, in which the unique germ cells are spermatogonia and primary spermatocytes, showed no apparent

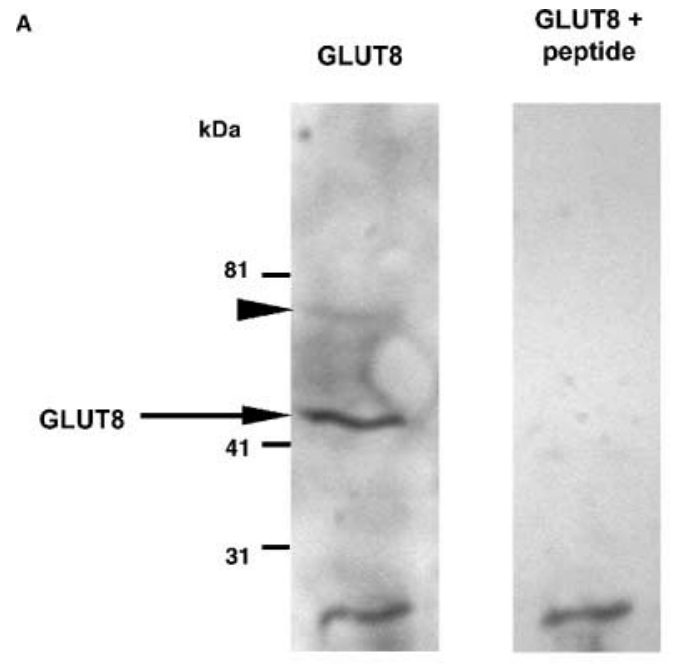

B

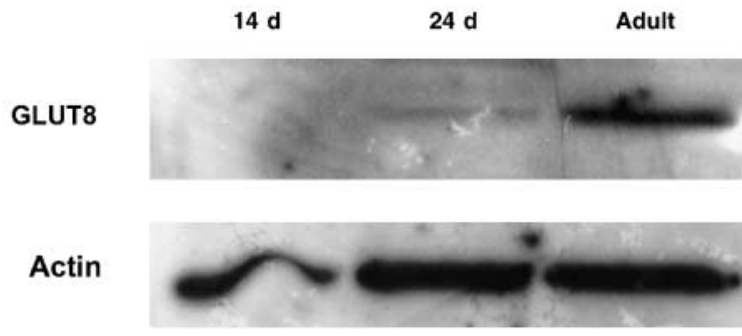

Figure 1 Immunodetection of GLUT8 by Western blot analysis and specificity of the antiserum. (A) Proteins $(40 \mu \mathrm{g})$ prepared from mouse testis were analyzed with anti-GLUT8 antibody (GLUT8) or antiGLUT8 antibody blocked with the immunogenic peptide (GLUT8 + peptide). The antiserum detected a $42-45 \mathrm{kDa}$ protein in adult testis (arrow). A second specific band was also detected at approximately $75 \mathrm{kDa}$ (arrowhead). (B) Differential expression of GLUT8 transporter in 10-week-, 24-day- and 14-day-old mouse testis. An amount of $40 \mu \mathrm{g}$ protein prepared from mouse testis was immunodetected with anti-GLUT8 and antiactin antibodies, as described. A representative gel is shown. 
Table 1 Distribution of immunohistochemical staining of GLUT8 in mouse testis as a function of testicular development. Empty cells indicate that the cell type was not yet present in the sections of the corresponding age - no staining, ++ moderate staining, +++ intense staining. In 24-day-old sections, not all tubules were stained, probably as related to the degree of development of each tubule.

\begin{tabular}{lccc}
\hline & \multicolumn{3}{c}{ Age of mice } \\
\cline { 2 - 4 } Testicular cell types & 14 days & 24 days & Adults \\
\hline Spermatogonia & - & - & - \\
Spermatocytes I & - & - & - \\
Spermatocytes II & & - & - \\
Round spermatids & & ++ & +++ \\
Elongated spermatids & & & +++ \\
Spermatozoa & & & +++ \\
\hline
\end{tabular}

GLUT8 immunoreactivity (GLUT8-IR) in any cell (Fig. 2B), thus confirming the absence of the GLUT8 protein expression at this age, as previously observed by Western blotting.

However, GLUT8-IR was evident in the testis of 24-dayand 8-10-week-old mice (Fig. 2E and H). Staining was confined to the seminiferous tubules and was absent from the interstitium. No signal was obtained when nonimmune serum was used instead of the primary antibody, (Fig. $2 \mathrm{~F}$ and $\mathrm{I}$ ) thereby confirming the specificity of the antibody reaction. Data also showed that GLUT8 was not expressed in all the testicular cells.

In 24-day-old mice, where spermatogonia, type I and type II spermatocytes, and round spermatids were present, evident GLUT8-IR was observed in the innermost part of some seminiferous tubules (Fig. 2E). Analysis at higher magnification showed that immunoreactivity was localized in round spermatids, while the other cells did not appear to express GLUT8 (Fig. 3A). GLUT8 immunostaining was restricted to a small area between the nucleus and cell membrane, presumably the acrosomic system.

In the testis of 8-10-week-old mice, which have already completed the first spermatogenic waves, and where all germ cells types (from spermatogonia to spermatozoa) may be identified, a heterogeneous staining in all seminiferous tubules was observed (Fig. 2H). Higher magnification of the sections showed that round and elongated spermatids were strongly immunoreactive with the antiGLUT8 antibody (Fig. 3). GLUT8 expression was always restricted to the forming acrosomic system in round and elongated spermatids, depicting the changing shape of this structure. The immunoreactive structure showed two different aspects in round spermatids: in recently formed round spermatids, GLUT8-IR was limited to a granule situated close to the nucleus that matches the so-called Golgi phase of the acrosome formation (Fig. 3B). As development of round spermatids progressed, the GLUT8-expressing structure adopted a flattened cap shape covering approximately half of the nucleus (Fig. 3C). Strongly expressed GLUT8-IR was also observed in the head of elongated spermatids. The immunoreactivity in these cells was observed in a long area corresponding to the acrosome (Fig. 3D). In both round and elongated spermatids, the strongest immunoreactivity was localized apposed to the acrosomic membrane, but substantial immunoreactivity was also evident inside the acrosomic vesicle (Fig. 3D and E). GLUT8-IR localization in the acrosomic system was confirmed by PAS staining (Fig. 2J). No signal was observed with the anti-GLUT8 antibody in less mature germinal cells, either Sertoli cells or Leydig cells.

Finally, GLUT8-IR was analyzed in spermatozoa obtained from mouse epididymis. Once again, immunoreactivity was present in the acrosome of these cells (Fig. 3F).

\section{mRNA expression of GLUT8 in mouse testis}

The expression of GLUT8 mRNA in the testis was confirmed by RT-PCR, using specific primers that amplify and detect a sequence with an expected size of $507 \mathrm{bp}$. A single transcript for GLUT8 was identified in 24-dayand 8-week-old mice, while no amplification product was observed in 14-day-old mice (Fig. 4). These results corroborate those obtained by immunochemistry, and they show that GLUT8 mRNA is not expressed in early phases of mouse testis development.

This observation is consistent with the above immunohistochemical data, indicating that GLUT8 expression occurs only at late spermatogenesis stages, as illustrated in Table 1, which summarizes the stage-specific expression of GLUT8 in the germ cells.

\section{Discussion}

Spermatogenesis in mammals is characterized by a welldefined sequence of mitotic and meiotic divisions leading to the production of mature spermatozoa (McCarrey 1993). In newborn mice, male germ-cell precursors undergo selfrenewal in the testis at days 1-7 postpartum. The early cell divisions lead to the development of types $A$ and $B$ spermatogonia, the latter of which undergo premeiotic replication, and enter meiosis as primary spermatocytes. Secondary spermatocytes proceed through a second meiotic division in which haploid germ cells are generated. These differentiate to form round spermatids, then elongated spermatids, and finally mature spermatozoa (spermiogenesis). The first round of spermatogenesis is followed by additional waves, enabling continuous sperm production throughout the life of the animals (McCarrey 1993, Zindy et al. 2001). In this study, we show that GLUT8 expression in mouse testis first appears when round spermatids are formed (after day 20 postpartum) (McCarrey 1993), persists during spermiogenesis, and is present in spermatozoa isolated from the epididymis. However, it is not observed in spermatogonia or spermatocytes (Table 1).

GLUT8 expression is always restricted to the acrosomic region throughout spermiogenesis by adopting the changing shape of the forming acrosomic system, and it is 

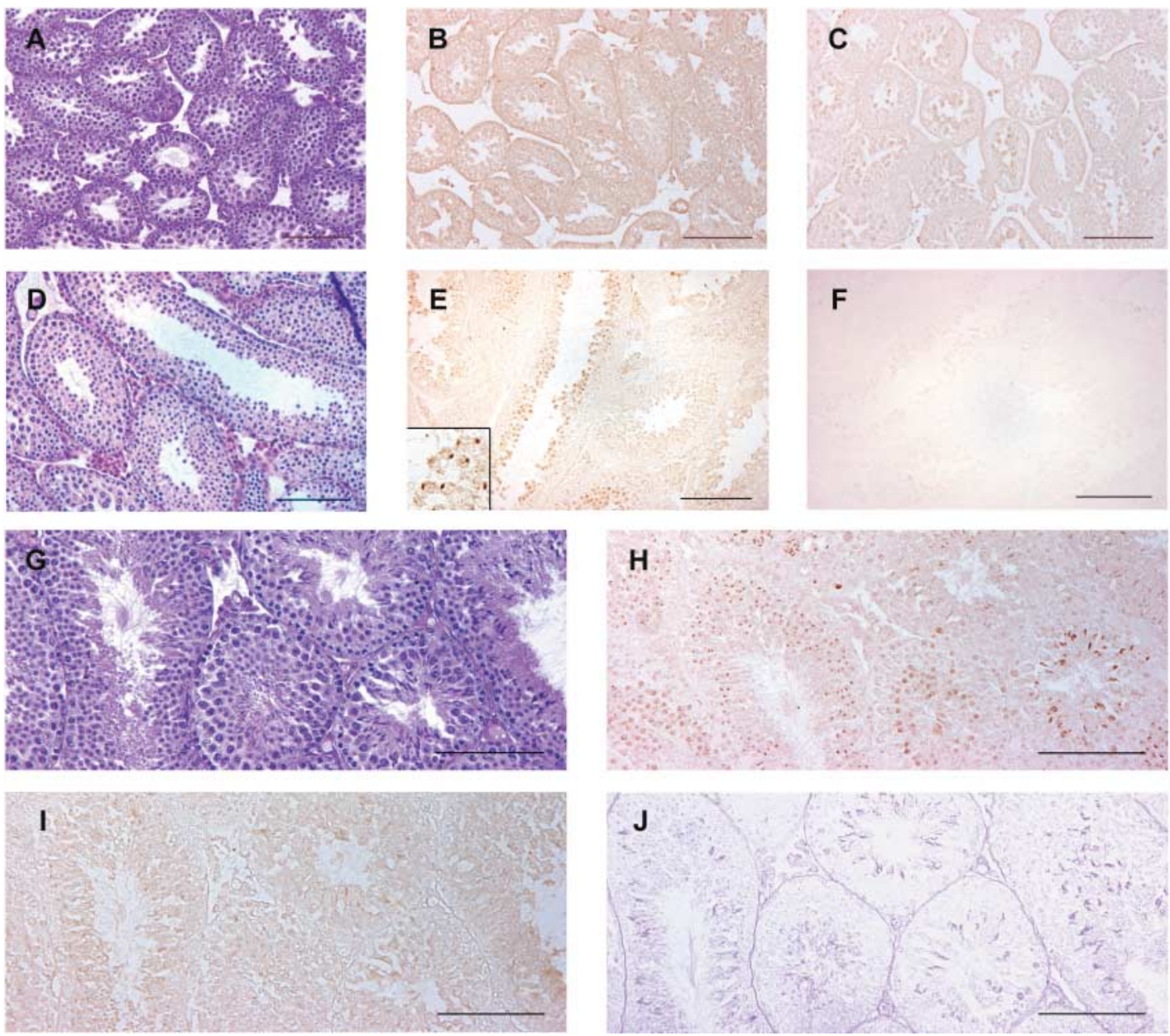

Figure 2 Immunodetection of GLUT8 in seminiferous tubules from 14-day-old (A-C), 24-day-old (D-F) and adult mice (G-J). Sections were incubated with a polyclonal anti-GLUT8 antibody (B, E and H). Note the absence of GLUT8-IR in 14-day-old mice (B), whereas some cells inside the tubules are labeled in the testis of 24-day-old ( $\mathrm{E}$, inset shows a higher magnification of GLUT8 immunostaining) and adult mice (H). Immunoreactivity disappeared when the sections were incubated with nonimmune serum (C, F and I). Panels $\mathrm{A}, \mathrm{C}$ and $\mathrm{E}$ show sections stained with hematoxylin and eosin. Pas staining (J) indicated that the GLUT8-IR structure was the acrosomic system. The scale bar is $80 \mu \mathrm{m}$. The results shown are representative of each age analyzed.

apparently absent from other locations. Previous reports have shown the testis to be the organ that expresses the highest GLUT8 levels (Doege et al. 2000, Ibberson et al. 2000, Schürmann et al. 2002, Chen et al. 2003). However, certain differences with respect to the concrete cells that express the transporter have been described. Our results confirm those reported by Schürmann et al. (2002). In addition, we have identified the round and elongated spermatids inside the testicular tubules as the GLUT8expressing cells. This is consistent with the fact that GLUT8 mRNA and GLUT8-IR are detected in 24-day-old mice, where round spermatids are present, and later, whereas in 14-day-old mice, a stage previous to spermatid differentiation, GLUT8 cannot be detected. Differences observed in other studies could be due to the different species studied (mouse versus rat), or to the techniques applied. Although no GLUT8 protein is detected before the spermatid stage, it cannot be ruled out that GLUT8
mRNA synthesis in the mouse could start at the previous stage to spermatocyte as in the rat (Ibberson et al. 2002). However, our results on GLUT8 mRNA analyses at different developmental stages show that no expression of GLUT8 mRNA is found at day 14 after birth, when leptotene, zygotene and pachytene phases are developed. Ibberson et al. (2002) indicated that GLUT8 is expressed specifically in the primary spermatocytes at these particular phases. Therefore, it is possible that GLUT8 has a species-differential cellular expression, and a similar pattern is presented in human and mouse (Schürmann et al. 2002).

It may be concluded from both this report and previous reports that GLUT8 is one of the main glucose transporters in the testis. Previous studies have shown the expression of GLUT1, GLUT2, GLUT3 and GLUT5 in testicular cells (Angulo et al. 1998, Burant \& Davidson 1994). These transporters are also expressed in spermatozoa (Angulo 

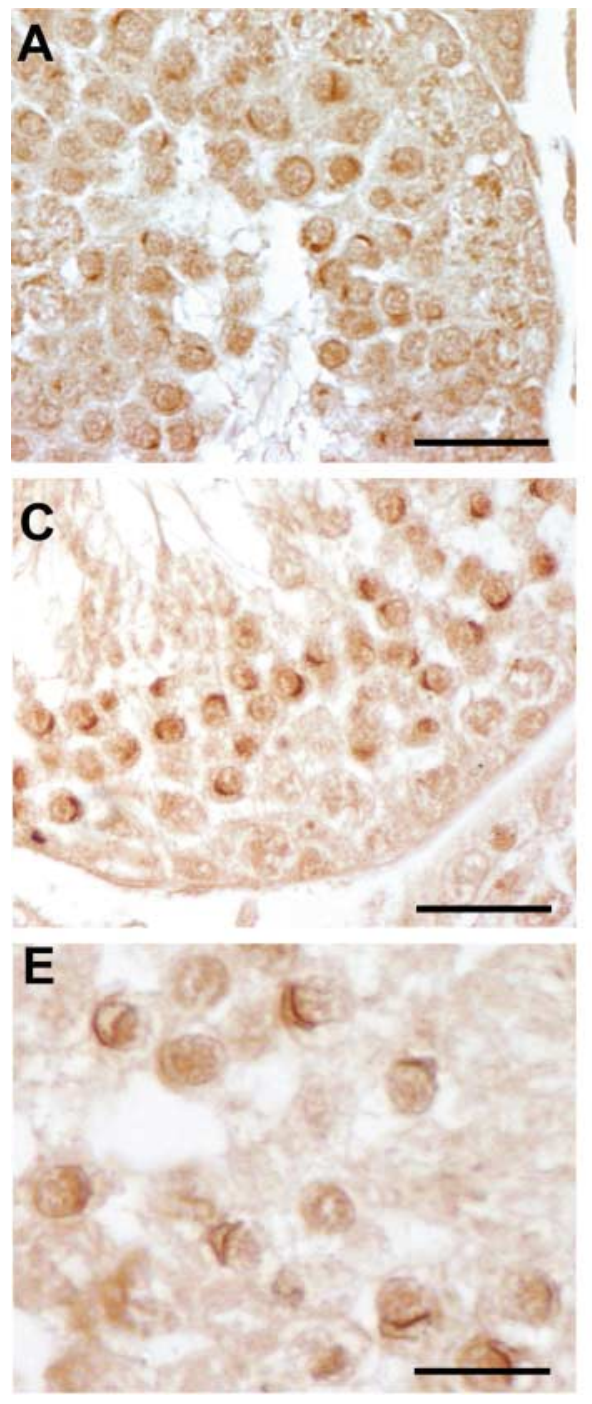
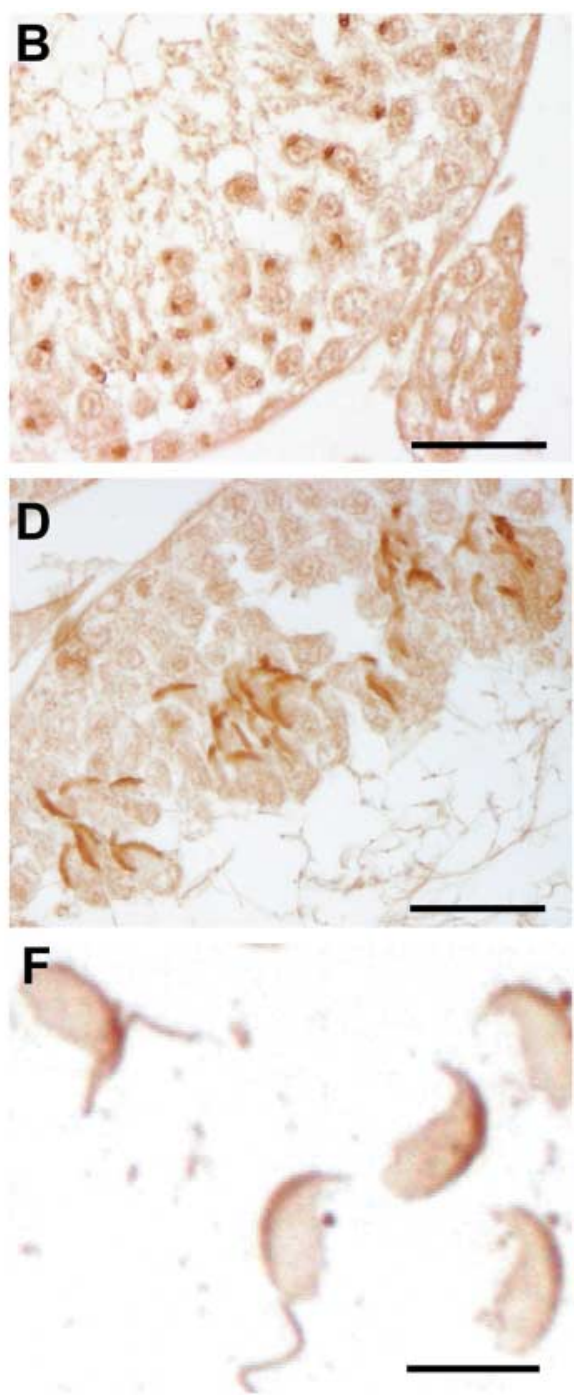

Figure 3 Specific cellular localization of GLUT8 in spermatogenic cells from both 24-day-old (A) and adult mice (B-F). The changing shape of the forming acrosomic system expressing GLUT8, from the Golgi phase $(A$ and $B)$, through the cap phase (A, C and E) to the acrosome phase (D), may be observed in the spermatids. GLUT8 was mainly associated with the acrosomic membrane of spermatids (E). GLUT8-IR was also detected in the acrosome (F) of spermatozoa isolated from the epididymis. The scale bar is $20 \mu \mathrm{m}$ in $\mathrm{A}-\mathrm{F}, 10 \mu \mathrm{m}$ in $\mathrm{E}$ and $5 \mu \mathrm{m}$ in $\mathrm{F}$. et al. 1998). It is interesting to note that both glucose transporter expression and glucose metabolic pathways seem to be compartmentalized in the sperm cell. In spermatozoa, the different glucose transporters show precise localization, although there is a degree of variability in different species (Angulo et al. 1998). In addition to GLUT8, it has been shown that GLUT1 is expressed in human, rat and bull sperm heads, while only GLUT2 and GLUT5 are expressed in rat and bull, and only GLUT3 is expressed in bull (Angulo et al. 1998). Thus, GLUT1-3 and GLUT5 are expressed in bull sperm head, whereas only GLUT2 and GLUT5 are expressed in rat and only GLUT1 is expressed in human sperm head. On the other hand, hexose metabolism is also compartmentalized: in the sperm head, the glucose metabolic pathway is pentose phosphate, while ATP is generated through glycolysis in the principal piece, and, through oxidative phosphorylation, in the midpiece (Urner \& Sakkas 2003). It is possible that this compartmentalization is related to
GLUT expression, and that concrete GLUT transporters supply glucose for each metabolic pathway.

The high expression levels suggest that GLUT8 plays an important role in glucose metabolism in male germ cells. It is unlikely that this role would be in the transport of glucose into spermatids, since these cells do not use glucose directly as a fuel supply, but the lactate produced by Sertoli cells (Bajpai et al. 1998) and GLUT8 is located in the intracellular compartment. In spermatids, however, GLUT8 could act as a transporter between the citosol and the acrosomic compartment to provide the subsequent glucose molecules for both the glycosylation and deglycosylation processes (Clermont \& Tang 1985, Bajpai et al. 1998). A similar function in the transport of glucose molecules between different intracellular compartments has been suggested for the hippocampus (Piroli et al. 2002). However, it is probable that GLUT8 function is even more complex in spermatozoa than in spermatids. Spermatozoa are transcriptionally inactive cells that have, then, to synthesize all the machinery that they will need 


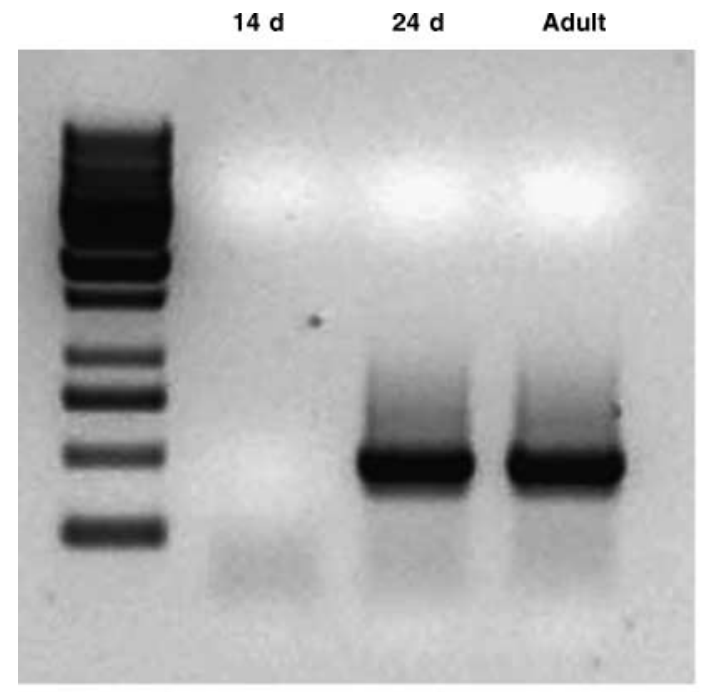

GLUT8

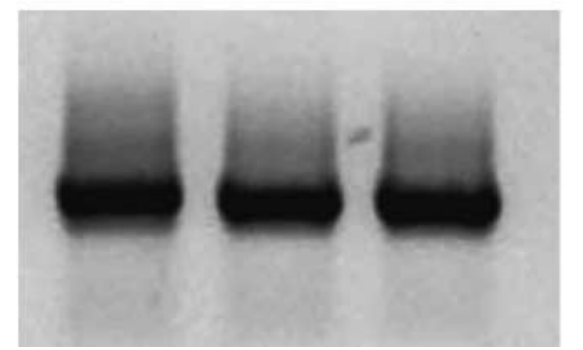

GAPDH

Figure 4 Mouse testis GLUT8 mRNA expression during development. First-strand cDNA synthesis and subsequent PCR of testis mRNA from 14-day-old, 24-day-old and adult mice. GLUT8 amplification was performed as described in Materials and Methods, and GAPDH was amplified as a control. No GLUT8 expression was detected from 14day-old mouse testis. A representative gel is shown.

at the previous spermatid stage. It is remarkable that other sperm glucose transporters, begin to be expressed at the spermatid stage (Angulo et al. 1998). In contrast to spermatids, glucose is necessary for the sperm function, and it has to be metabolized by spermatozoa for zona pellucida penetration and sperm-oocyte fusion, and to ensure that tyrosine phosphorylation occurs during capacitation (Urner \& Sakkas 2003). Capacitation of mammalian spermatozoa is a functional process that requires the consumption of significant amounts of energy. Glucose seems to be the major energy source needed to maintain in vitro capacitation in mice and human spermatozoa, since this sugar induces much higher penetration rates and capacitation-like changes than do other monosaccharides, such as fructose or mannose (Travis et al. 2004).

GLUT8 must be translocated from the acrosome to the cell membrane for glucose transport into the sperm cells. GLUT8 translocation from subcellular compartments to the cell membrane has been reported in insulin-treated blastocysts through insulin-like growth factor receptor-1 (IGFR-1) activation (Carayannopoulos et al. 2000, Pinto et al. 2002). A similar change in GLUT8 localization could occur in sperm cells during the capacitation or sperm-oocyte interaction, and GLUT8 could be located in the cell membrane under accurate stimuli to allow glucose entry into the cell. IGF-1 is a candidate as such a stimulus since it is found in the seminal plasma, and its receptor IGFR-1 is present in the sperm acrosome (Naz \& Padman 1999). It has also been shown that both the sperm plasma membrane and the acrosome represent cytologic targets for insulin (Silvestroni et al. 1992). Recent studies (Aquila et al. 2005) have shown that insulin is expressed in, and secreted from, human ejaculated spermatozoa, with higher secretion in the capacitated sperm, suggesting that insulin plays a role in capacitation. Since GLUT4, the most important and studied insulinregulated transporter, has not been detected in the testis or spermatozoa (Burant \& Davidson 1994, Angulo et al. 1998, Schürmann et al. 2002), GLUT8 is the best candidate for regulation by members of the insulin-IGF system in testis. However, more studies are necessary to determine the precise role of GLUT8 in testicular cells. The developmentally regulated expression accompanying its cellular location and its function in other tissues suggest that this transporter might also play a role in the fuel supply of spermatozoa, and in the traffic of sugars during the capacitation and fertilization processes.

\section{Acknowledgements}

This study was supported by grants BFI2002-03590, SAF 2004-00228 from the Spanish government and the European Regional Development Fund (ERDF/FEDER), and grants PRUCH-02/18 and PRUCH-03/20 from the Cardenal HerreraCEU University. We would also like to thank the Histology and Biochemistry Units of the UCH-CEU University for assistance. Fellowship support for O Gómez and A Romero from the Cardenal Herrera-CEU University is gratefully acknowledged. The authors declare that there is no conflict of interest that would prejudice the impartiality of this scientific work.

\section{References}

Angulo C, Rauch MC, Droppelmann A, Reyes AM, Slebe JC, Delgado-Lopez F, Guaiquil VH, Vera JC \& Concha II 1998 Hexose transporter expression and function in mammalian spermatozoa: cellular localization and transport of hexoses and vitamin C. Journal of Cellular Biochemistry 71 189-203.

Aquila S, Gentile M, Middea E, Catalano S \& Ando S 2005 Autocrine regulation of insulin secretion in human ejaculated spermatozoa. Endocrinology $146552-557$.

Bajpai M, Gupta G \& Setty BS 1998 Changes in carbohydrate metabolism of testicular germ cells during meiosis in the rat. European Journal of Endocrinology 138 322-327.

Bradford M 1976 A rapid and sensitive method for the quantitation of microgram quantities of protein utilizing the principle of protein-dye binding. Analytical Biochemistry 72 248-254.

Burant CF \& Davidson NO 1994 GLUT3 glucose transporter isoform in rat testis: localization, effect of diabetes, and comparison to human testis. American Journal of Physiology. Regulatory, Integrative and Comparative Physiology 267 R1488-R1495. 
Carayannopoulos MO, Chi MM, Cui Y, Pingsterhaus J, McKnight RA, Mueckler M, Devaskar SU \& Moley KH 2000 GLUT8 is a glucose transporter responsible for insulin-stimulated glucose uptake in the blastocyst. PNAS $\mathbf{9 7} 7313-7318$.

Chen Y, Nagpal ML \& Lin T 2003 Expression and regulation of glucose transporter 8 in rat Leydig cells. Journal of Endocrinology $\mathbf{1 7 9}$ $63-72$.

Clermont Y \& Tang XM 1985 Glycoprotein synthesis in the Golgi apparatus of spermatids during spermiogenesis of the rat. Anatomical Record 213 33-43.

Doege H, Schürmann A, Bahrenberg G, Brauers A \& Joost HG 2000 GLUT8, a novel member of the sugar transport facilitator family with glucose transport activity. Journal of Biological Chemistry 275 16275-16280.

Gorovits N, Cui L, Busik JV, Ranalletta M, Hauguel De-Mouzon S \& Charron MJ 2003 Regulation of hepatic GLUT8 expression in normal and diabetic models. Endocrinology 144 1703-1711.

Ibberson M, Uldry M \& Thorens B 2000 GLUTX1, a novel mammalian glucose transporter expressed in the central nervous system and insulin-sensitive tissues. Journal of Biological Chemistry 275 4607-4612.

Ibberson M, Riederer BM, Uldry M, Guhl B, Roth J \& Thorens B 2002 Immunolocalization of GLUTX1 in the testis and to specific brain areas and vasopressin-containing neurons. Endocrinology $143276-284$.

Joost HG \& Thorens B 2001 The extended GLUT-family of sugar/polyol transport facilitators: nomenclature, sequence characteristics and potential function of its novel members. Molecular Membrane Biology 18 247-256.

Laemmli UK 1970 Cleavage of structural proteins during the assembly of the head of bacteriophage T4. Nature 227 680-685.

Leblond CP \& Clermont Y 1952 Spermiogenesis of rat, mouse, hamster and guinea pig as revealed by the periodic acid-fuchsin sulfurous acid technique. American Journal of Anatomy 90 167-215.

McCarrey JR 1993 Development of the germ cell. In Cell and Molecular Biology of the Testis, pp 58-89. Eds C Desjardins \& LL Ewing. New York: Oxford University Press.

Mesonero JE, Tanfin Z, Hilly M, Colosetti P, Mauger JP \& Harbon S 2000 Differential expression of inositol 1,4,5-trisphosphate receptors types 1,2 and 3 in rat myometrium and endometrium during gestation. Biology of Reproduction $63532-537$.

Naz RK \& Padman P 1999 Identification of insulin like growth factor (IGF)-1 receptor in human sperm cell. Archives of Andrology 43 $153-159$.

Pinto AB, Carayannopoulos MO, Hoehn A, Dowd L \& Moley KH 2002 Glucose transporter 8 expression and translocation are critical for murine blastocyst survival. Biology of Reproduction 66 1729-1733.

Piroli GG, Grillo CA, Hoskin EK, Znamensky V, Katz EB, Milner TA, McEwen BS, Charron MJ \& Reagan LP 2002 Peripheral glucose administration stimulates the translocation of GLUT8 glucose transporter to the endoplasmic reticulum in the rat hippocampus. Journal of Comparative Neurology 452 103-114.

Russell LD, Ettlin RA, Sinha Hikim AP \& Clegg ED 1990 Histological and Histopathological Evaluation of the Testis. Clearwater, FL: Cache River Press.

Schiffer M, Susztak K, Ranalletta M, Raff AC, Böttinger EP \& Charron MJ 2005 Localization of the GLUT8 glucose transporter in murine kidney and regulation in vivo in nondiabetic and diabetic conditions. American Journal of Physiology. Renal Physiology 289 F186-F193.

Schürmann A, Axer H, Scheepers A, Doege H \& Joost HG 2002 The glucose transport facilitator GLUT8 is predominantly associated with the acrosomal region of mature spermatozoa. Cell and Tissue Research 307 237-242.

Silvestroni L, Modesti A \& Sartori C 1992 Insulin-sperm interaction: effects on plasma membrane and binding to acrosome. Archives of Andrology 28 201-211.

Travis AJ, Tutuncu L, Jorgez CJ, Ord TS, Jones BH, Kopf GS \& Williams CJ 2004 Requirements for glucose beyond sperm capacitation during in vitro fertilization in the mouse. Biology of Reproduction 71 139-145.

Uldry M \& Thorens B 2004 The SLC2 family of facilitated hexose and polyol transporters. Pflugers Archiv: European Journal of Physiology 447 480-489.

Urner F \& Sakkas D 2003 Protein phosphorylation in mammalian spermatozoa. Reproduction 125 17-26.

Wood IS \& Trayhurn P 2003 Glucose transporters (GLUT and SGLT): expanded families of sugar transport proteins. British Journal of Nutrition 89 3-9.

Zindy F, den Besten W, Chen B, Rehg JE, Latres E, Barbacid M, Pollard JW, Sherr CJ, Cohen PE \& Roussel MF 2001 Control of spermatogenesis in mice by the cyclin D-dependent kinase inhibitors $18^{\text {Ink4c }}$ and p19 ink4d. Molecular and Cellular Biology 21 3244-3255.

Received 7 April 2005

First decision 19 May 2005

Revised manuscript received 1 September 2005

Accepted 5 September 2005 